\title{
Association Between Health Risk Knowledge and Risk Behavior Among Medical Students and Residents In Yerevan
}

\author{
Tereza Khachkalyan ${ }^{1}$, Varduhi Petrosyan ${ }^{1}$, Krikor Soghikian ${ }^{1,2}$ \\ ${ }^{1}$ College of Health Sciences, American University of Armenia, Yerevan, Armenia \\ ${ }^{2}$ Kaiser Permanente Division of Research, Oakland, California, USA
}

\begin{abstract}
Background. The relationship between risk knowledge, attitude, and behavior among different population groups is complex and has not been sufficiently explored. It was especially interesting to look at some aspects of this relationship among future health professionals (medical students and medical residents) assuming their detailed exposure to medical knowledge and health risks. The objectives of this study were to investigate the association between risk behavior and health risk knowledge/perception among medical students and residents in Yerevan, Armenia and examine the degree and direction of association between individual characteristics and risk behavior. Methods. A descriptive-analytical crosssectional survey design was used. Risk behavior and health risk knowledge/perception were assessed through an anonymous self-administrated questionnaire. Risk-taking behavior was measured as the number of all risk behaviors in a lifetime. Knowledge/perception was measured by the extent to which subjects agreed with risk-related statements. T-test, ANOVA, and linear regression modeling were used to analyze associations between total risk, health knowledge/perception, and individual characteristics. Results. Total risk was statistically significantly associated with age, gender, education, marital status, and having children; no association was found with birth order or attitude toward religion. Knowledge/perception about health risks was not associated with behaviors of interest after adjustment for potential "confounders." There was a statistically significant interaction between marital status and knowledge/perception. Decrease in the number of reported risk behaviors with higher knowledge/perception score in this population was less among married participants than single participants. Conclusion. In this preliminary study, knowledge/perception of health risk did not appear to be a statistically significant predictor of risk behavior. Considering the limitations of this study, more research is needed to adequately assess the effect of knowledge and perception of health risk on risk behaviors of medical students and residents in Armenia.
\end{abstract}

(c) 2006 Californian Journal of Health Promotion. All rights reserved.

Keywords: risk behavior, medical students, Armenia, health risk

\section{Introduction}

Public health interventions are aimed at improving health, often by changing behaviors of people. One of the key assumptions underlying in the basis of health interventions, and, in particular, health educational interventions, is that the relationship between health knowledge and health practices is positive (Kilander, 2001). According to such "rational models of human perception," communicating health knowledge increases the likelihood that one will practice healthy behaviours (Cook \& Bellis, 2001; Fishbein, Guina, 1996).
Such theoretical models were not always confirmed by research. The literature showed that people engaging in risky behaviors were often aware of the risk but failed to change their behavior (Cook \& Bellis, 2001; Maswanya, Moji, Takemoto, 1999; Garba, Aboubacar, Barkire, Vera, Sellin, Chippau, 2001; Schmidt, Krasnik, Brendstrup, Zoffmann, Larsen, 1989; Harding, Anadu, Gray, Champeau, 1999). Graham et al. (2000) revealed that the reported behavior of female adolescents was inconsistent with the high scores obtained in their knowledge of safer sex practices; their knowledge did not 
appear to influence their risky behavior. It was also shown that university students frequently use tanning lamps despite the fact that $90 \%$ of them had adequate knowledge of the adverse effects of ultraviolet exposure (Knight, Kirinchich, Farmer, Hood, 2002). Moreover, risk-taking behavior (e.g., smoking, alcohol drinking and drug use) was not rare even in well-informed groups of the population such as doctors and medical students (Cook \& Bellis, 2001; Maswanya et al. 1999). Several studies investigated lifestyles of students attending medical school in various countries, and the results of these surveys revealed that unhealthy behaviors were widely practiced by students and graduates of medical institutions (Marks, 1999; Piko, 2002; Siegel-Itzkovich, 2002; Williams \& Goebert, 2003).

Nevertheless, the necessity of knowledge should not be underestimated in motivating behavioural change (Hawa, Munro, Doherty-Poirier, 1998). Knowledge was essential in developing attitudes towards distinct behaviours and assisting individuals with making decisions and taking action toward healthy behaviours. Thus, health education or health risk information should be an important part of complex public health interventions aimed at modifying a person's behavior (Hawa et al., 1998).

The complex relationship between a person's knowledge, attitude, and behavior was not sufficiently explored. A better understanding of the influence of this knowledge on attitudes and risk reduction in a particular culture could significantly help in designing effective educational programs and health messages.

Investigating the association between certain risk behaviors of health professionals, both practicing physicians and medical students, and their knowledge about the adverse effects of these behaviors on health, becomes important since "health professionals primarily focus on change processes that affect general well being" (Huddleston, Mertesdorf, Araki, 2002).

Researchers in many countries showed that medical students and graduates of medical colleges, as well as physicians, did not practice what they preach. High prevalence of smoking, drinking, low level of physical activity, unsafe sex practices, and obesity were observed in studies conducted in Israel, Japan, and the United States (Ohida, Sakurai, Mochizuki, Kamal, Takemura, Minowa, Kawahara, 2001; Piko, 2002; Siegel-Itzkovich, 2002). For example, while assessing sexual behavior of resident physicians and non-medical graduate students (law students and master's-level social work students) in Hungary, no difference was recorded, in spite of the fact that the resident physicians received instruction about healthy sexual behavior (Williams \& Goebert, 2003).

No data were available in this area in Armenia except for limited statistics on a few risk behaviours like smoking and illegal drug use. For example, the prevalence of smoking in Armenia was $69.0 \%$ for men and $6.2 \%$ for women in 2000 (NIH, 2003; WHO, 2001). Healthcare professionals had very high smoking rates: $56.8 \%$ of doctors smoked. Moreover, $39.1 \%$ of physicians smoked in the presence of their patients, $34.7 \%$ did not think that they harmed themselves, and $45.7 \%$ did not consider that they harmed other people (NIH, 2003).

Data about drug use came primarily from unofficial sources, including less than rigorous assessments, consultant reports and the news media. According to the Armenian Ministry of Internal Affairs, the local market for narcotics was not very large, but the number of substance abusers has been on the rise since 1998 (Drug policy and health in Armenia, 2002). In addition, the rising number of individuals testing positive for HIV associated with drug use has become a concern in Armenia (Drug policy and health in Armenia, 2002). The number of registered drug abusers increased from 610 in 1996 to 1438 in 1998; according to the Ministry of Internal Affairs, the real number of drug abusers could be 15-20 times this figure (WHO, 2001).

The statistics of the last five years showed an increase in the incidence rates of syphilis and gonorrhea among teenagers by 2.2 and 2.9 times, respectively (People for healthy life stile, 2000). Therefore, investigating health risk 
knowledge and its association with risk behaviors, was of practical value in Armenia.

This preliminary survey of risk knowledge and practice in Armenia was designed to fill the data gap and create a basis for further research in this area. The specific objectives of the study were:

1. To investigate the association between health risk knowledge and risk behaviors among medical students and medical residents living in Yerevan.

2. To examine the degree and direction of association between individual characteristics (age, gender, education, marital status, having children, birth order and belief in God) and risk behavior among medical students and medical residents living in Yerevan.

\section{Methods}

The study design was a cross-sectional descriptive/analytical survey. The survey was conducted during July and September 2003.

The sampling frame included all 528 fourth and fifth year students at Yerevan State Medical University (MU) and all 625 medical residents at the National Institute of Health (NIH) at the time of the study. Sampling was done in two-stages: groups of participants were selected randomly, and then all the members of the selected groups of students/residents not refusing to participate were recruited into the study group The ultimate sample size was calculated to be 140 after adjusting for the design effect and response rate (estimated to be 90\%) (Aday, 1996).

The study instrument was an anonymous selfadministrated questionnaire adapted from the study conducted by Cook and Bellis in Liverpool and Manchester, United Kingdom, in 2001 (Cook \& Bellis, 2001). The instrument was translated into Armenian and was pretested among 10 participants including doctors, medical residents, and Master of Public Health students. Basic demographic questions included age, gender, and marital status, number of children, number of brothers and sisters, and birth order. The behavioral risk questions were divided into 10 categories: diet, sexual behavior, alcohol use, tobacco use, illegal drug use, car accidents, personal hygiene, neglect, involuntary behaviour risks, and other. The second set of items was related to the knowledge and perception of the risk associated with behavior. The knowledge/perception items were in the form of statements with four-point scale (Likerttype). Statements were presented in a random order and in true and false directions in order to minimize interviewee error or response bias: for example, always answering the same way (so called “yea/nay saying”).

Risk taking behavior (total risk) was measured as the sum of all risk behaviors during lifetime (Table 1).

For this study, the variables "health risk knowledge" and "health risk perceptions" were combined into one variable "health risk knowledge/perception.” This variable was measured by summing the scores assigned to each answer category in the Likert-type scale. The majority of the intervening variables included in the survey were categorical (gender, marital status, education (being student or resident), belief in God, and birth order). In addition, continuous variables "age" (age in years) and "children" (number of children) were categorized for the analyses.

Independent t-test and ANOVA global test were used to investigate the total risk by categories of demographic characteristics (Fink, 1995; Pagano \& Gauvreau, 1993). Simple and multiple linear regressions were applied to explore the total and direct (adjusted) associations between the total risk and risk knowledge/perception (Pagano \& Gauvreau, 1993; Weisberg, 1985). The statistical analyses were performed using the STATA (version 7.0) statistical software package. The Institutional Review Board/ Committee on Human Research at the American University of Armenia approved the study. 
Table 1

Study Variables

\begin{tabular}{|c|c|c|c|}
\hline Type of variables & $\begin{array}{c}\text { Level of } \\
\text { measurement }\end{array}$ & Measurement & $\begin{array}{l}\text { Method of } \\
\text { Construction }\end{array}$ \\
\hline \multicolumn{4}{|l|}{ Dependent } \\
\hline Total risk & Interval & $\begin{array}{l}\text { Number of reported risk } \\
\text { behaviors }\end{array}$ & Index $^{a}$ \\
\hline \multicolumn{4}{|l|}{ Independent } \\
\hline $\begin{array}{l}\text { Health risk (Knowledge/ } \\
\text { perception) }\end{array}$ & Interval & $\begin{array}{l}\text { Extent of agreement with } \\
\text { statements about risk- } \\
\text { related information }\end{array}$ & Summative scale $^{\mathrm{b}}$ \\
\hline \multicolumn{4}{|l|}{ Intervening } \\
\hline Age & Interval & Years & Number of years \\
\hline Gender & Categorical & Female/Male & Coding \\
\hline Birth order & Ordinal & Oldest/Youngest/Middle & Coding \\
\hline Marital status & Categorical & Single/Married & Coding \\
\hline Children & Ratio & Number of children & Number of children \\
\hline Belief in God & Categorical & Yes/No & Coding \\
\hline
\end{tabular}

\section{Results}

The interviewer approached 168 medical students/residents; five of them refused to participate. More than half of the participants (53.9\%) were medical residents (Appendix A). Respondents' median age was 24 years (range $19-55$ ) with $69.9 \%$ of the sample being females. The majority of men residents were single while more than half of the women residents were married; most of both female and male students were single. Most of the participants (79.8\%) believed in God.

Respondents' median age was 24 years (range 19-55) with $69.9 \%$ of the sample being females. The majority of men residents were single while more than half of the women residents were married; most of both female and male students were single. Most of the participants (79.8\%) believed in God.

The range of the number of reported risk behaviors (dependent variable) was from three to 19 with median of 10 and standard deviation 3.2. The most frequently reported behaviors were "Eating snacks like chocolate in a day" (84.7\%), "Walking through moving traffic to cross a road" (79.2\%), "Having a dessert with the main meal" (62.7\%), and "Getting skin burnt when on a sunny holiday" (58.3\%). None of the participants reported ever having sex with someone of the same sex. One participant reported ever using anabolic steroids (0.6\%), and three ever having a sexually transmitted disease (1.8\%), six were treated in an emergency department because of an accident (3.7\%), and six (3.7\%) reported that they had tried to commit a suicide.

The results of between group comparison tests revealed that total risk was statistically significantly associated with all demographic characteristics of participants (age category, gender, marital status, having children, and education) except their birth order and attitude toward religion (Table 2). 
Table 2

Association between Total Risk of Respondents and Their Individual Characteristics (t-test for between 2 Independent Group Comparison) $(\mathrm{N}=163)$

\begin{tabular}{|l|c|c|c|c|}
\hline \multicolumn{1}{|c|}{ Demographic characteristics } & $\begin{array}{c}\text { Difference in } \\
\text { the total risk }\end{array}$ & $\mathbf{9 5 \% ~ C I ~}$ & $\begin{array}{c}\boldsymbol{t} \text { - } \\
\text { statistic }\end{array}$ & $\begin{array}{c}\boldsymbol{p} \text { - } \\
\text { value }\end{array}$ \\
\hline Gender (female vs. male) & -2.8 & $-3.8 ;-1.8$ & -5.5 & 0.0000 \\
\hline Marital status (single vs. married) & 1.7 & $0.6 ; 2.8$ & 3.1 & 0.0023 \\
\hline Having children (no children vs. children) & 1.8 & $0.7 ; 2.9$ & 3.2 & 0.0017 \\
\hline Education (student vs. resident) & 1.8 & $0.9 ; 2.8$ & 3.7 & 0.0003 \\
\hline Belief in God (yes vs. no) & -0.3 & $-1.6 ; 1.0$ & -0.5 & 0.6292 \\
\hline
\end{tabular}

* Difference in the total risk scores between groups with and without the characteristic

Further statistical analysis demonstrated that participants aged 40-50 years were significantly less likely than their younger (less than 25 years old) colleagues to report risk behaviors $(\mathrm{p}<0.019)$. Similarly, the residents reported less risk behaviors than did the students $(\mathrm{p}<0.0003)$. More risk taking was reported by single than married participants $(\mathrm{p}<0.013)$, and by the participants without children than parents $(p<0.002)$. Comparison of total risk by birth order did not show statistically significant differences although analysis of variance showed a marginally statistically significant variability between groups $(\mathrm{p}<0.048)$. Finally, the analysis demonstrated a significant relationship between reported risk behaviors and gender: men appeared to be more risk taking than women $(\mathrm{p}<0.0001)$.

The association between health risk knowledge/perception and risk taking behavior was examined using simple linear regression (SLR) analysis (Table 3). The results suggested no significant unadjusted linear relationship between study variables.

In the consequent step of analysis, the association between total risk and health knowledge was adjusted for intervening variables using multiple linear regression (MLR) modeling (Table 4). Of the intervening variables, only age and gender had some "confounding" effect on this association. However, none of the models demonstrated any statistically significant adjusted relationships between risk knowledge/perception and risk behaviour (no MLR coefficient was significantly different from zero). Thus, knowledge/ perception about health risks was not statistically significantly associated with behaviors of interest investigated in this study even after adjusting for the potential "confounders" age, gender, education, marital status, birth order, having children, and belief in God.

An assumption was made that an interaction of two covariates might influence the change in the total risk scores. Interaction terms were generated, and MLR models were investigated in order to see if the relationship between knowledge and behavior of this cohort could be influenced by different individual characteristics (Table 4).

Of seven intervening variables, marital status and having children revealed statistically significant interactions with knowledge/ perception variable. The model including the interaction term marital status- knowledge/ perception was selected as the "optimal" model; goodness of fit was checked through inspection of residuals (Pagano \& Gauvreau, 1993; Weisberg, 1985). Nevertheless, the model explained only $12 \%$ of the variability in the total risk (Table 4). 
Table 3

Results of Multiple Linear Regression Models for Total Risk Behaviour (N=163)

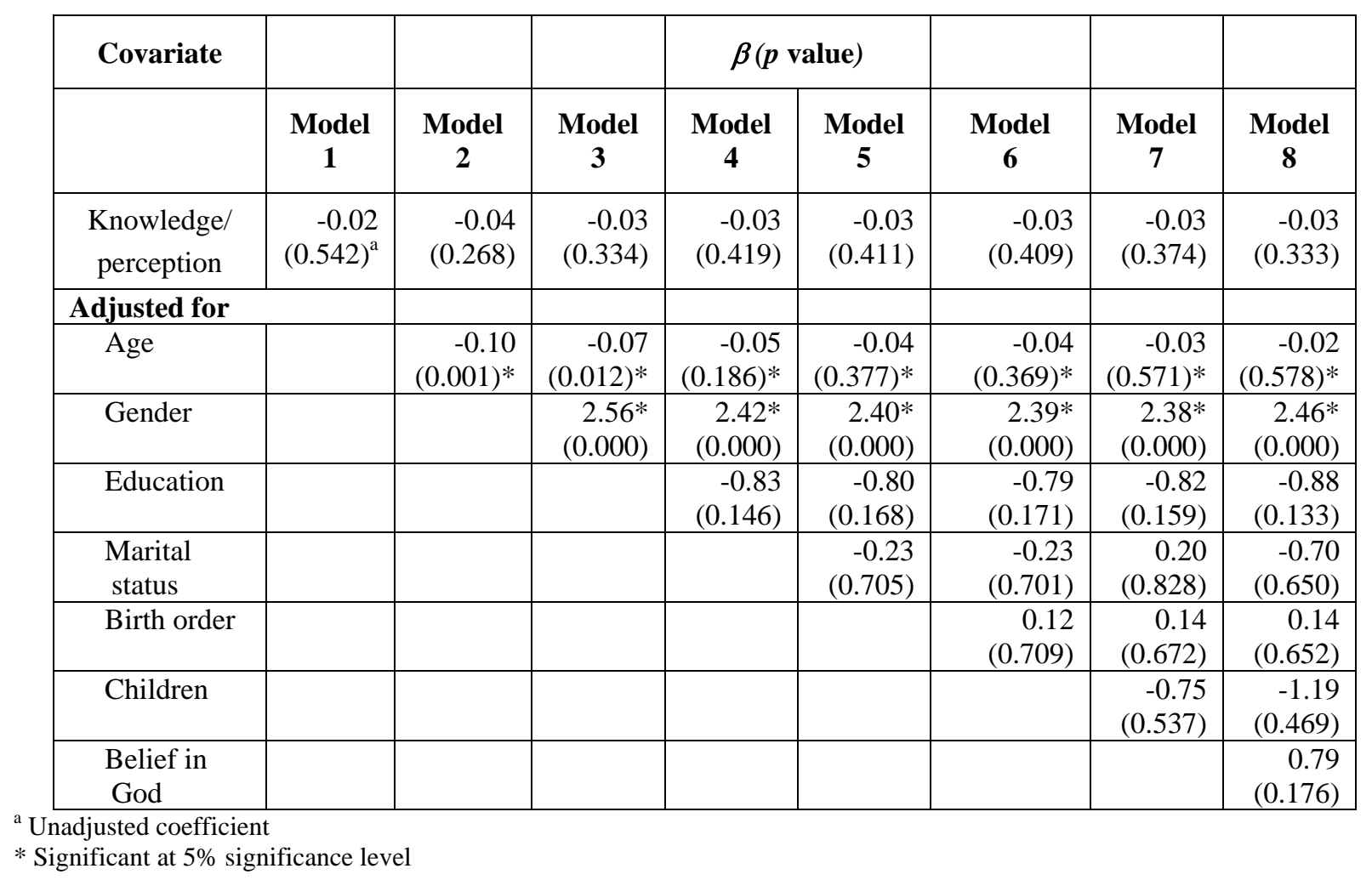

Table 4

Association Between Total Risk and Knowledge/Perception by Marital Status (N=163)

\begin{tabular}{|l|r|r|r|r|c|c|}
\hline \multicolumn{1}{|c|}{ Covariate } & \multicolumn{1}{c|}{$\boldsymbol{\beta}$} & \multicolumn{1}{c|}{ S. E. } & \multicolumn{1}{c|}{ - statistic } & $\boldsymbol{p}$ - value & $\mathbf{9 5 \%}$ CI & $\mathbf{R}^{\mathbf{2}}$ \\
\hline Knowledge/ perception & -0.4 & 0.1 & -3.3 & 0.001 & {$[-0.6 ;-0.2]$} & 0.12 \\
\hline Marital status & -29.2 & 8.8 & -3.3 & 0.001 & {$[-46.5 ;-11.9]$} & \\
\hline $\begin{array}{l}\text { Knowledge-marital status } \\
\text { (interaction term) }\end{array}$ & 0.3 & 0.1 & 3.1 & 0.002 & {$[0.1 ; 0.4]$} & \\
\hline
\end{tabular}

According to this model, one unit higher level of the health risk knowledge score was associated with a decrease of the total risk score by 0.4 (95\% CI $=[-0.6 ;-0.2])$ among single participants. This decrease of the total risk score was much smaller among married participants; being married predicted from 0.1 to 0.4 less decrease in the score of reported risk behaviors in students and residents with one point higher knowledge/perception score.

\section{Discussion}

It is important to emphasize that this preliminary study had some limitations. Although the instrument was pretested and certain changes were made to make it more relevant to Armenia, the Armenian version was not validated. 
Interviewee bias could have affected the study results. It was not always possible to avoid some discussion between participants while they were completing the questionnaires, particularly when completing the sections on knowledge and perception. In addition, some of the participants did not fully trust the confidentiality of the survey and were concerned that their answers could be identified or their teachers might have access to them. Therefore, they could have denied health risk behaviors and chosen only healthy behaviors. Moreover, single young people could have felt freer in answering sensitive questions. Hence, our findings should be considered as preliminary results and further investigation of this issue would be needed.

The preliminary results demonstrated statistically significant differences between students and residents, and married and single participants. However, these differences could only be attributed to age and gender. Being a student in this population also predicted being younger and single. The great majority of students were less than 25 years old. Given that most of the items in the questionnaire referred to risk behaviors in a lifetime, it was possible that recall bias was not as much of a problem among young students and they reported more risk behaviors than older residents. Cook and Bellis (2001) also reported that younger people were more likely to take risks. Significantly higher prevalence of risk behaviour among men was also consistent with the findings reported in the literature (Cook and Bellis, 2001).

Finally, it was demonstrated that those who were married or had children (these were mainly the same respondents) reported significantly less risk behaviours. Moreover, having a family appeared to be an effect modifier in the relationship between health knowledge/ perception and behaviour. Changes in health knowledge/ perception had more impact on the behaviour if a person was single.

The variables birth order and belief in God were investigated in order to compare the results of the current study with the findings of other similar studies. Birth order appeared not to be a significant predictor of selected behaviours, which was consistent with data reported by other authors (Cook and Bellis, 2001). A significant portion $(79.8 \%)$ of students and residents in this study reported believing in God. However, there was no evidence of any statistically significant association between this characteristic and total risk behaviour. This finding could be explained by an increasing interest in religion in recent years that possibly had not yet turned into a strong conviction that could influence one's behaviour.

The results of this study were consistent with the findings reported by investigators who conducted similar studies in the United States, as well as in various countries in Europe and Asia (Cook and Bellis, 2001; Knight et al., 2002; Maswanya et al., 1999; Piko, 2002; Schmidt et al., 1989; Siegel-Itzkovich, 2002). It was demonstrated that, in general, risk taking behaviour and high scores of health risk knowledge were not significantly associated. However, there were no available data regarding those kinds of relationships in Armenian culture. This preliminary survey provided valuable information about the issue and created a basis for further research on the relationship between health risk knowledge/ perception and risk behaviour in Armenia. This would facilitate effective and culturally appropriate communication of health knowledge to modify unhealthy behaviors in the Armenian population.

\section{References}

Aday, I. A. (1996). Designing and conducting health surveys: A comprehensive guide. San Francisco: Jossey-Bass.

Cook, P. A., \& Bellis, M. A. (2001). Knowing the risk: relationships between risk behavior and health knowledge. Public Health, 115, 54-61.

Drug Policy and Health in Armenia. (2002). A profile prepared by the drug law and health policy resource network. Retrieved October 10, 2003, from http://www.drugpolicy.org/docUploads/armenia.pdf 
Fink, A. (1995). How to sample in surveys. London: SAGE Publications.

Fishbein, M., \& Guina, M. (1996). Behavioral science and public health: a necessary partnership for HIV prevention. Public Health Reports, Special Issue: Behavioral Science in HIV Prevention, 111, 5.

Garba, A., Aboubacar, A., Barkire, A., Vera, C., Sellin, B., Chippau, J.P. (2001). Impact of health education programs on the control of urinary bilharziasis in Niger. Sante, 11, 35-42.

Graham, M., Duff, E., Marilyn, W., Bailey, E. Y. (2000). Risk factors for sexually transmitted diseases among female adolescents. West Indian Medical Journal, 49, 23-24.

Harding, A. K., Anadu, E. C., Gray, L. A., Champeau, D. A. (1999). Nigerian university students' knowledge, perceptions, and behaviors about HIV/AIDS: are these students at risk? Journal of the Royal Society of Health, 119(1), 23-31.

Hawa, R., Munro, B. E., Doherty-Poirier, M. (1998). Information, motivation and behavior as predictors of AIDS risk reduction among Canadian first year university students. The Canadian Journal of Human Sexuality, 7(1), 9-10.

Huddleston, S., Mertesdorf, J., Araki, K. (2002). Physical activity behavior and attitudes toward involvement among physical education, health, and leisure services pre-professionals. College Student Journal, 36, 555-573.

Kilander, H. F. (2001). Testing health information of students and adults. Journal of School Health, 71(8), 411-413.

Knight, J. M., Kirinchich, A. N., Farmer, E. R., Hood, A. F. (2002). Awareness of the risks of tanning lamps does not influence behavior among college students. Archives of Dermatology, 138, 13111315.

Marks, A. (1999). Psychological factors affecting condom use in North American society. Retrieved May 20, 2003, from http://faculty.uccb.ns.ca/ gcarre/courses/health/SafeSex.htm

Maswanya, E. S., Moji, K., Takemoto, T. (1999). Knowledge, risk perception of AIDS and reported sexual behavior among students in secondary schools and colleges in Tanzania. Health Education Research, 14(2), 185-196.

NIH. (2003). Statistic data from Department of Epidemiology and Medical Informatics, National Institute of Health. Retrieved May 21, 2003, from http://www.tobaccocontrol.am/st-epidem.html

Ohida, T., Sakurai, H., Mochizuki, Y., Kamal, A. M., Takemura, S., Minowa, M., Kawahara, K. (2001). Smoking prevalence and attitudes toward smoking among Japanese physicians. Journal of the American Medical Association, 285, 2643-2648.

Pagano, M., and Gauvreau, K. (1993). Principles of biostatistics. Belmont, CA: Doxbury Press.

People for Healthy Life Style. (2000). Statistic about healthy behavior in Armenia. Retrieved May 23, 2003, from http://www.iatp.am/resource/ngo/phl/links2/stat.htm

Piko, B. F. (2002). Does knowledge count? Attitudes toward smoking among medical, nursing, and pharmacy students in Hungary. Journal of Community Health, 27, 269-277.

Schmidt, K., Krasnik, A., Brendstrup, E., Zoffmann, H., Larsen, S. O. (1989). Attitudes towards HIV infection and sexual risk behavior. A survey among Danish men 16-55 years of age. Scandinavian Journal of Social Medicine, 17(4), 281-286.

Siegel-Itzkovich, J. (2002). Lifestyles of medical students in Jerusalem are “shocking.” Student British Medical Journal, 445-446.

Weisberg, S. (1985). Applied linear regression (2nd ed.). St. Paul, MN: John Wiley.

WHO Regional Office for Europe. (2001). Highlights on health in Armenia. Retrieved May 22, 2003, from http://www.euro.who.int/document/e72377.pdf

Williams, J. K., \& Goebert, D. (2003). Assessing sexual health behaviors of resident physicians and graduate students. Academic Psychiatry, 27, 44-49.

\section{Acknowledgements}

We would like to thank Dr. Marie Diener West (Johns Hopkins Bloomberg School of Public Health) for her assistance and valuable input in this study. We are also thankful to Lusine Yeghiazaryan from Walsh 
University, Ohio, and the MPH 2003 cohort at the American University of Armenia for their valuable comments and suggestions.

Our thanks are directed to Penny Cook from Liverpool John Moors University for providing the copy of "Health and Risk Profile" questionnaire. We also express our gratitude to the chairs of departments at the Yerevan State Medical University and National Institute of Health and all participants of the surveys for their support and cooperation.

Author Information

Tereza Khachkalyan, MS, MPH

College of Health Sciences

American University of Armenia

Yerevan, Armenia

Varduhi Petrosyan, MS, $\mathrm{PhD}^{*}$

College of Health Sciences

American University of Armenia

40 Marshal Baghramian

Yerevan 375019

Armenia

Ph.: 3741-512-564

Fax.: 3741-512-566

E-mail: vpetrosy@jhsph.edu or vpetrosi@aua.am

Krikor Soghikian, MD, MPH

College of Health Sciences

American University of Armenia

Yerevan, Armenia

AND

Kaiser Permanente Division of Research

Oakland, California, USA

* corresponding author 


\section{Appendix A}

Demographic Characteristics of the Study Participants

\begin{tabular}{|c|c|c|c|c|}
\hline \multirow[b]{2}{*}{ Demographic Characteristics } & \multicolumn{2}{|c|}{ Students $(n=75)$} & \multicolumn{2}{|c|}{ Residents (n=88) } \\
\hline & Female n (\%) & Male n (\%) & Female n (\%) & Male n (\%) \\
\hline \multicolumn{5}{|l|}{ Age by categories } \\
\hline$<25$ & $42(97.7)$ & 29 (90.7) & $15(21.1)$ & $6(35.3)$ \\
\hline $25-30$ & - & $1(3.1)$ & 33 (46.5) & $8(47.1)$ \\
\hline $31-40$ & - & $1(3.1)$ & 9 (12.7) & $2(11.7)$ \\
\hline $41-50$ & $1(2.3)$ & $1(3.1)$ & $11(15.5)$ & $1(5.9)$ \\
\hline$>50$ & - & - & $3(4.2)$ & - \\
\hline \multicolumn{5}{|l|}{ Marital status } \\
\hline Single & $41(95.4)$ & $30(93.7)$ & $31(43.7)$ & $12(70.6)$ \\
\hline Married & $2(4.6)$ & $2(6.3)$ & 40 (56.3) & $5(29.4)$ \\
\hline \multicolumn{5}{|l|}{ Having children } \\
\hline Yes & $2(4.6)$ & $2(6.3)$ & $37(52.1)$ & $4(23.5)$ \\
\hline No & $41(95.4)$ & $30(93.7)$ & 34 (47.9) & $13(76.5)$ \\
\hline \multicolumn{5}{|l|}{ Belief in God } \\
\hline Yes & $36(83.7)$ & $22(68.7)$ & $59(83.1)$ & $13(76.5)$ \\
\hline No & 7 (16.3) & $10(31.3)$ & 12 (16.9) & 4 (23.5) \\
\hline
\end{tabular}

